\title{
La Bioética en el Proyecto de Código Civil y Comercial de la nación
}

\section{SALVADOR DARÍo BERGEL}

\section{Profesor Titular Cátedra Unesco Bioética de la UBA}

1. El tratamiento legislativo del Código Civil y Comercial de la Nación redactado por una Comisión de juristas designados por el Poder Ejecutivo ha generado como no podía ser de otra forma- una natural conmoción en diversos estamentos de la sociedad.

La presente contribución no constituye un comentario exegético de las normas proyectadas, tema que -obviamente- excedería el marco propuesto. Simplemente apunta a marcar los puntos de contacto entre la bioética y el derecho civil, en ocasión del dictado de un nuevo Código.

El proyecto que ha sufrido modificaciones durante su tratamiento en la Cámara de Senadores, seguramente será modificado antes de su sanción definitiva, ya que lejos de agotarse el debate con lo acordado en la cámara de origen, ha generado nuevos planteos y observaciones.

Por tal razón, en estas reflexiones prefiero ceñirme al proyecto original tal como lo redactaran sus autores.

Si bien desde lo jurídico formal un código tiene la misma jerarquía normativa que cualquier ley, desde lo sustancial reúne en un texto la totalidad de las normas 
relativas a una rama del derecho, sistematizadas de forma tal que le otorgan cierta uniformidad.

El Código Civil que nos rige data de fines del Siglo XIX y pese a los reiterados parches que sufrió durante su vida no puede negarse que fue concebido para un mundo y una sociedad que poco o nada tienen que ver con el presente

La bioética como multi e interdisciplina no existía para ese entonces. Su nacimiento se produjo un siglo después y gran parte de los temas que hoy ocupan su atención eran desconocidos.

La circunstancia de haber incorporado en el texto proyectado una serie de principios bioéticos, ha concitado interesantes debates. Rodotá -ilustre jurista y bioeticista- recuerda que existe una generalizada y persistente dificultad social a la hora de metabolizar las innovaciones científicas y tecnológicas cuando éstas inciden en particular sobre el modo en que nacemos y morimos, sobre la construcción del cuerpo en la era de la reproducción tecnológica, sobre la posibilidad misma de proyectar la persona. La sensación de desconcierto es comprensible pues se están viendo afectados los sistemas de parentesco y el orden entre generaciones, la unidad misma de la persona. Es la antropología profunda del ser humano la que de repente en pocos años ha sido puesta en discusión ${ }^{1}$.

Estas reflexiones nos ilustran acerca del clima que naturalmente crea el tratamiento de esta temática.

\footnotetext{
${ }^{1}$ Rodotà, S.: La vida y sus reglas: entre el derecho y el no derecho, Edit. Trotta, Madrid 2010, p. 31.
} 
El proyecto cumple en parte con el propósito de llenar un vacío legal, al menos en forma sistemática, lo que no es poca cosa.

Debe considerárselo como un punto de partida, perfectible en el tiempo no sólo como consecuencia de los debates que con seguridad suscitará, sino también como consecuencia de la emergencia de nuevas cuestiones traídas por el incesante fluir en el campo de las ciencias de la vida.

2. Tal como puede advertirse de una simple lectura del texto proyectado, el Capítulo 3 del Título I (Persona humana), bajo la denominación "Derechos y actos personalísimos", contiene la mayor parte de las normas y los principios vinculados con bioética (inviolabilidad de la persona humana, actos de disposición sobre el propio cuerpo, prácticas prohibidas en el campo de la genética, investigaciones en salud humana, consentimiento informado y directivas médicas anticipadas).

La categoría de "derechos personalísimos" constituye una novedad en nuestra legislación que responde a un largo requerimiento de la doctrina vernácula. Si bien Vélez Sarsfield no se refirió a ellos en forma expresa, no puede asegurarse que los haya ignorado. La nota al artículo 2312 del Código -ubicada en los derechos reales- expresa que "hay derechos y los más importantes que no son bienes, tales como ciertos derechos que tienen su origen en la existencia del individuo mismo al que pertenecen como la libertad, el honor, el cuerpo de la persona, la patria potestad, etc.”.

Hoy podemos caracterizar a los derechos personalísimos como derechos absolutos, extra patrimoniales, indisponibles, que acompañan al hombre a través de su existencia. Desde esta perspectiva estos derechos se insertan en la categoría más amplia de los derechos humanos y a través de ellos se relacionan con la bioética. Cuando 
hablamos de derechos humanos en la actual coyuntura -lo hemos señalado- cabe partir de una concepción amplia, elástica, perfectible en el curso del tiempo, que emergiendo del campo normativo se proyecta sin más limitaciones para expresar un conjunto de valores fundamentales que se vinculan en forma cada vez más inescindible a la esencia y a la proyección de la persona humana.

Estas circunstancias no pasaron inadvertidas a la Comisión Redactora, que al referirse a la incorporación de los derechos de la personalidad destaca que se ha tomado en consideración la incorporación a la Constitución del derecho supranacional de los derechos humanos, cuya reglamentación infra-constitucional debe tener lugar en el Código Civil; conceptos que naturalmente compartimos.

Enunciado el vínculo entre derechos personalísimos y derechos humanos resulta tarea sencilla el insertar en esta constelación a la bioética. La bioética nació y evolucionó del brazo de los derechos humanos. Prácticamente todos los documentos internacionales sobre la materia vinculan ambos conceptos; constituyendo una muestra acabada de ello la reciente declaración de la UNESCO de 2005 titulada "Declaración Universal sobre Bioética y Derechos Humanos".

3. Los artículos 51 y 17 del proyecto incorporan dos de los principios centrales de la bioética contemporánea: el respeto a la dignidad del individuo y la no comercialidad del cuerpo humano y sus partes.

Sabido es que en el campo de la bioética el concepto de dignidad humana ha dado lugar a múltiples interpretaciones. Desde quienes le asignan una supremacía indiscutible, considerándolo el eje central en función del cual pivotea la disciplina, hasta 
quienes consideran que es un concepto que no aporta mayores precisiones y que carece de utilidad.

Creo que al hablar de los derechos personalísimos, la mención de la dignidad de la persona humana es insoslayable. Tal dignidad significa en el esclarecido pensamiento de Atienza ser particularmente capaz de exigir derechos; agregando que el principio de la dignidad es absoluto, las razones basadas en la dignidad derrotan todas las otras razones en todas las circunstancias, de manera que no es un principio que quepa ponderar con otros ${ }^{2}$.

Alguna vez se sostuvo que la dignidad es un derecho. Tal vez concebirlo en esa forma importa reducir su valor. Por nuestra parte consideramos que es el paraguas bajo el cual encuentran cobijo los derechos fundamentales; por ello se lo ubica en un plano superior.

La ya mencionada Declaración de la UNESCO coloca a la dignidad humana y a los derechos humanos como el primero de los principios de la disciplina.

El proyecto de Código -correctamente a mi entender- encabeza el capítulo de los derechos personalísimos estableciendo en el artículo 51 que la persona humana es inviolable y en cualquier circunstancia tiene derecho al reconocimiento y respeto de su dignidad. Adviértase que lo que se enuncia como derecho es el "reconocimiento y respeto de su dignidad".

\footnotetext{
${ }^{2}$ Atienza, M.: Sobre el cuerpo y la dignidad humana, en: Casado, M. (coord.): Sobre la dignidad y los principios, Edit. Civitas, Madrid 2009, p. 73.
} 
La inviolabilidad de la dignidad humana es una garantía que posibilita a todo el mundo, incluso a los interesados, el establecimiento de restricciones a su significado y alcance. La libertad y la dignidad -recuerda Rodotá- pertenecen a la esfera de lo no negociable, de lo que está fuera del mercado ${ }^{3}$.

El artículo 17 consagra en la legislación civil el principio de no comercialidad del cuerpo humano y sus partes.

El derecho sobre el cuerpo humano y sus partes -expresan los fundamentos del texto- no tiene un valor económico, sino afectivo, terapéutico, científico, humanitario y social y sólo puede ser disponible por sus titulares cuando se configure alguno de esos valores y según lo dispongan las leyes especiales.

Desde tiempos lejanos se consideró que el cuerpo humano y sus partes debían quedar al margen del derecho patrimonial y en consecuencia no podían ser enajenados. Sin embargo, no existieron normas de derecho positivo que lo establecieran. Se trataría -según expresa Mezaud- de una regla tradicional, de un axioma jurídico que nadie experimentó la necesidad de discutir ${ }^{4}$.

A juicio del ilustre Carbonier, identificar a la persona con el cuerpo humano atribuye a éste un emplazamiento peculiar en el ámbito jurídico y en cierta forma lo dota de un carácter sagrado.

El problema jurídico surge -según lo refiere la Comisión Redactora- cuando se advierte que el cuerpo humano y sus partes, tales como piezas anatómicas, órganos,

\footnotetext{
${ }^{3}$ Rodotà, S.: Op. cit., p. 75.

${ }^{4}$ Mezaud, L.: Los contratos sobre el cuerpo humano, en: ADC, Enero-Marzo 1953, p. 81.
} 
tejidos, células, genes, pueden ser separados, aislados, identificados y luego transplantados, patentados, transferidos comercialmente. Un modo de resolverlo agrega- es recurrir a los derechos de la personalidad. El derecho a la integridad personal se extiende tanto al cuerpo como a las piezas anatómicas una vez extraídas del cuerpo; mientras sea posible la identificación de éstas en la persona 5 .

Más adelante explica la Comisión que el valor configura un elemento de la tipicidad de la noción de bien y está calificado porque es afectivo (representando algún interés no patrimonial para su titular), terapéutico (tiene un valor para la curación de enfermedades), científico (tiene un valor para la experimentación), humanitario (tiene valor para el conjunto de la humanidad), social (porque tiene valor para el conjunto de la sociedad).

En todos los casos se trata de valores que califican la noción de bien como un elemento de la tipicidad.

El tema tiene indudables implicaciones bioéticas. El tráfico de órganos -por mencionar sólo alguno- es moneda común en el mundo de hoy, poniendo de manifiesto la explotación de las necesidades de los individuos que a juicio de Berlinger están excluidos de la vida ${ }^{6}$.

4. El artículo 56 prohíbe los actos de disposición del propio cuerpo que ocasionen una disminución permanente a su integridad o resulten contrarios a la ley, la moral o las buenas costumbres, excepto que sean requeridos para el mejoramiento de la

\footnotetext{
${ }^{5}$ Bergel, S.D.: Aportes para un estatuto de las partes separadas del cuerpo, en: La Ley, LXXV No 131 , Julio 2011.

${ }^{6}$ Berlinger, G.: Bioética cotidiana, Edit. Siglo XXI, México 2002, p. 151.
} 
salud de la persona y excepcionalmente de otra persona, de conformidad con lo dispuesto por el ordenamiento jurídico.

En la exposición de motivos se aclara que las limitaciones se fundan en principios bioéticas. En esencia el texto reitera lo que ya traía el Código italiano de 1942.

Aquí la norma va más allá de la finalidad económica que puede presidir el acto. Todo lo que se relaciona con el cuerpo y sus partes se ubica en el ámbito de los derechos personalísimos y no resulta suficiente para el legislador que se recurra a la autonomía del sujeto.

Cabría - en este ámbito- interrogarse si puede el derecho permitir la existencia de un derecho de propiedad del hombre sobre sí mismo (sobre su cuerpo) o sobre los elementos que lo integran, sin producir un cambio sustancial en los conceptos jurídicos de propiedad y de sujeto del derecho. El cuerpo en su integridad no puede ser apropiado por el hombre -tal como lo destaca Andorno- el ser humano no puede desdoblarse dentro de sí mismo entre un "sujeto de derecho" y un "objeto de derecho". El orden jurídico al resistirse a la idea de un derecho de disposición sobre su propio cuerpo se erige de algún modo en garante de la unidad de una persona y de su dignidad ${ }^{7}$.

5. El artículo 57 prohíbe las prácticas destinados a alterar la constitución genética de la descendencia, exceptuando los que tienden a prevenir enfermedades genéticas o predisposición a ellas; siguiendo las aguas de la legislación francesa de 1994.

\footnotetext{
${ }^{7}$ Andorno, M.: La persona humana en el proyecto de unificación de los Códigos Civil y Comercial, en: Revista de Derecho de Familia de las Personas, Año IV, Nº 7, Agosto 2012, p. 232.
} 
Esta norma tiende a evitar la manipulación genética con fines eugenésicos, peligro que se asienta en los formidables avances de la genética y de la genómica producidos desde mediados del siglo pasado.

Los avances de la investigación en los campos de la genética y de la biología molecular hicieron concebir algunos intentos de reiterar - esta vez con un mejor bagaje científico- aventuras eugenésicas que parten de priorizar la herencia genética por sobre cualquier otro factor.

Hoy sabemos que no hay genotipos óptimos ni genotipos normales, sino constelaciones de genotipos que permiten a sus portadores vivir y reproducirse con éxito en los ambientes en que habita. Normalidad $\mathrm{y}$ anormalidad son en todo caso características del fenotipo y no del genotipo ${ }^{8}$.

La nueva eugenesia se alimenta, al decir de Iañez Pareja, de tres factores principales:

-la idea de que las cualidades (positivas y negativas) de los seres humanos poseen una esencial determinación genética (uno de los puntos centrales del credo eugenista de todas las épocas);

-la expectativa de que las tecnologías biológicas podrían moldear la naturaleza humana interviniendo en su sustrato genético;

\footnotetext{
${ }^{8}$ Pena, J.: Conflictos paradigmáticos e a ética do Projeto Genoma Humano, en: Revista de la Universidad de San Pablo No 24, p. 68.
} 
-la aplicación al campo de la procreación del derecho de los individuos a realizar opciones libres 9 .

No obstante el hecho que los intentos de restablecer las ideas eugenésicas parecen bastante en retirada ante el cúmulo de evidencias científicas que vuelven a dar a los factores ambientales en la herencia tanto o más relevancia que a los genéticos, considero que la norma proyectada se justifica claramente dada la relevancia que merece el destino de la especie humana.

6. El artículo 58 bajo el título de "investigaciones en salud humana" consagra los principios centrales que la legitiman.

Es tan importante en este caso la normativa como su ubicación sistemática.

Al ubicar la investigación con seres humanos dentro de los derechos personalísimos muestra el legislador la interrelación que guarda el tema con los derechos humanos y se inclina por el carácter nacional de su regulación. La falta de precisiones sobre el tema había dado lugar a que en nuestro medio se lo considerara de incumbencia provincial, como un derecho no delegado, lo que en la práctica hubiera ocasionado problemas por la multiplicidad de soluciones que se podrían generar.

Ahora, de aprobarse el Código, la legislación sobre investigación con seres humanos queda en claro que pertenece a la órbita nacional.

El tema de las investigaciones con seres humanos está muy ligado a los orígenes de la bioética como multidisciplina en la segunda mitad del siglo pasado. Fruto de tales

\footnotetext{
${ }^{9}$ Iañez Pareja, E.: Retos éticos ante la nueva eugenesia, en: Romeo Casabona, C.: La eugenesia hoy, Edit. Comares, Granada 1999, p. 197.
} 
preocupaciones fueron el Código de Nüremberg, la Declaración de Helsinki y el Informe Belmont, documentos todos ellos que ratifican la dignidad del individuo y su autonomía, ante las reiteradas violaciones de los derechos humanos.

Lo que consagra el articulado propuesto son principios elementales de general aplicación. De todos modos considero que es imprescindible el dictado de una normativa completa sobre la investigación con seres humanos, tarea que queda delegada al Congreso Nacional.

Es importante destacar que el inciso f) del artículo 58 institucionaliza en la órbita del derecho civil a los comités de ética de investigación, llamados a dar su aprobación previa a tales investigaciones.

Los comités en cualquiera de sus formas -ha expresado F. Lolas- son una expresión de la contextura dialoguista de la bioética, movimiento y paradigma de la medicina que ha entronizado la deliberación y el diálogo como garante de un trabajo éticamente aceptable.

La Declaración Universal de la UNESCO citada consagra en su artículo 19 como uno de los principios de la disciplina que deberían crearse, promover y apoyar al nivel que corresponda, comités de ética independientes, pluridisciplinarios y pluralistas con miras a evaluar los problemas éticos, jurídicos, científicos y sociales pertinentes sustentados por los proyectos de investigación relativos a seres humanos.

7. El artículo 19 en cuanto se pronuncia respecto al comienzo de la existencia de la persona humana ya ha dado lugar a un debate interesante, que nos ilustra acerca de la compleja relación entre bioética y derecho. 
El proyecto se inclina por un doble régimen, según se trate de la fecundación en el seno materno o in Vitro.

Este régimen ha sido cuestionado tanto por los sectores científicos como desde la visión bioética y desde una visión influenciada por criterios religiosos.

Una fuerte ofensiva han promovido los sectores vinculados a la Iglesia, a los que se unió una parte considerable de la doctrina civilista. Para ellos no cabe formular ningún tipo de distinción, ya que a partir de la concepción (unión de los gametos) en cualquier ámbito en que se produzca, se origina el comienzo de la vida de la persona humana.

Para el sector científico carece de fundamentos la distinción proyectada, remitiéndose a lo que informa la ciencia sobre la complejidad de la determinación del comienzo de la vida.

Otros sectores que provienen de la bioética sostienen que el comienzo de la persona humana debe trasladarse al nacimiento con vida del niño, tal como ocurre en varios países europeos.

El tema presenta una cierta complejidad por las cuestiones que suscita y por los efectos jurídicos que proyecta.

De receptarse el criterio de ubicar el comienzo de la vida en la concepción, se crearía un problema serio con relación a la admisión de la fecundación médica asistida y del diagnóstico preimplantatorio, ya que no sería admisible manipular personas ni crioconservarlas. 
De aceptarse la otra tesis unitaria que apunta a un único momento que no es la concepción, sino el nacimiento, se podrían presentar problemas en cuanto a la compatibilidad de la norma con el artículo $4^{\circ}$ del Pacto de San José de Costa Rica, incorporado a la Constitución Nacional.

El debate generado no puede darse por concluido, ya que es posible que el texto sea modificado en la instancia legislativa, en atención a los múltiples pronunciamientos que suscitó.

Hemos adherido al texto propuesto por la comisión por entender que encaja más con las normas constitucionales aplicables.

Las opiniones científicas, por más acertadas que sean en ese ámbito, deben considerar que aquí se trata de elaborar un texto legal que debe compatibilizarse con otros de orden superior y que no necesariamente deben coincidir los criterios científicos con la norma proyectada cuyo objetivo es determinar en forma precisa el comienzo de la existencia de la persona humana para el derecho.

Si no se observan estos aspectos nos ubicamos fuera del contexto. Un ejemplo nos ubica en los límites posibles y en las consecuencias de su violación.

El Comité Nacional de Ética de las Ciencias y las Tecnologías del MINCYT debatió durante varios encuentros las normas del proyecto vinculadas con ciencia y tecnología. Fruto de lo debatido se redactó un proyecto de modificación del artículo 19 que reza: "Comienzo de la existencia. La persona humana es el resultado de un proceso que comienza con la concepción en la mujer y se completa durante la gestación. En el caso de técnicas de reproducción humana asistida comienza con la implantación del 
embrión en la mujer y se completa durante la gestación, sin perjuicio de lo que prevea la ley especial para la protección del embrión no implantado".

A los ojos de un jurista esta norma no cumple con el propósito central de determinar con precisión el comienzo de la existencia de la persona, centro de imputación de derechos y obligaciones. Puede ser científicamente correcta pero no lo es jurídicamente, ni es útil para los fines propuestos. Traigo a colación las agudas observaciones de Labrousse Riou, destacada bioeticista y civilista gala: "los médicos y los biólogos se agotan en descripciones puramente naturalistas del comienzo del desarrollo del ser humano para tratar de deducir de ellas las calificaciones jurídicas; aunque los indicadores biológicos no son potentes para juzgar por sí mismos una representación natural ${ }^{10}$.

8. El artículo 59 se refiere al consentimiento informado para actos médicos e investigaciones en salud.

Conforme lo consideró el Comité Nacional de Bioética italiano, el consentimiento informado constituye la legitimación y el fundamento del acto médico.

Es una condición indispensable de la relación médico-paciente y de la investigación con seres humanos. Se trata de una decisión voluntaria realizada por persona autorizada y capaz, tomada después de un procedimiento informativo y deliberativo tendiente a la aceptación de un tratamiento específico o experimental, conociendo la naturaleza del mismo, sus consecuencias y sus riesgos ${ }^{11}$.

\footnotetext{
${ }^{10}$ Labrousse Riou, C.: Écrits de bioéthique, PUF, Paris 2007, p. 161.

${ }^{11}$ Clotet, J.: Bioética uma aproximaçao, Edipurcs, Porto Alegre 2003, p. 89.
} 
El artículo trata de dos tipos de consentimiento: el otorgado para la atención médica del individuo y el dado para someterse a una experimentación con seres humanos.

El tema, en lo que se refiere a la actuación médica, ya había sido abordado en la ley de derechos de los pacientes $\mathrm{N}^{\mathrm{o}}$ 26529, Capítulo 3, no así en lo referente a la experimentación con seres humanos.

En lo que toca al primer supuesto cabe recordar que tradicionalmente la relación médico-paciente pasó por la existencia de un paternalismo que colocaba al paciente en una situación de inferioridad y al médico en un ámbito superior, con poderes de decisión

El consentimiento informado parte de la idea central de reconocer al paciente su autonomía. El respeto de la autonomía de uno de los sujetos -observa Borsellino- a la par que excluye el paternalismo por parte del otro, implica el reconocimiento a éste de una misma autonomía. La autonomía a diferencia del paternalismo es un criterio que da lugar a relaciones simétricas, relaciones en las cuales el sujeto se halla en un pie de igualdad $^{12}$.

En torno al segundo supuesto el consentimiento tiene un mayor valor y su violación importa mayores consecuencias para quien lo desconoció.

\footnotetext{
${ }^{12}$ Borsellino, P.: Bioética, entre autonomía y derecho, Edit. Cajica, México 2004, p. 111.
} 
En la investigación médica el sujeto que se presta como voluntario puede ser un enfermo o puede ser un sujeto sano, que por diversas circunstancias se presta a la experimentación.

Las consecuencias que puede tener el tratamiento experimental al cual se somete son desconocidas, ya que las pruebas anteriores en humanos o en no humanos son de naturaleza distinta. Por ello, la necesidad de contar con una información adecuada sobre los riesgos y consecuencias que derivan de la experimentación es fundamental, en tanto se halla en juego la vida o la salud del individuo.

Más allá de la circunstancia que debe dictarse una ley especial sobre experimentación con seres humanos en nuestro medio, el tratamiento del consentimiento informado en el Código tiene un especial significado, que no podemos desconocer.

Cabe señalar que el consentimiento del sujeto tanto en la intervención médica preventiva, diagnóstica o terapéutica, como en el caso de la investigación científica, constituye uno de los principios receptados por la Declaración Universal sobre Bioética y Derechos Humanos (artículo 6).

9. Dentro de una idea global de autonomía del ser humano con relación a las decisiones que hacen a su vida y a su salud, tenemos las denominadas "directivas médicas anticipadas" que incorpora el Código en su artículo 60.

La incesante evolución de las ciencias de la vida ha llegado a extremos tales como la utilización de tecnología médica destinada a prolongar la vida del paciente, aún cuando su salud se encuentra gravemente comprometida. 
Esto llevó a admitir la existencia de directivas médicas anticipadas que en sustancia constituyen una forma de prolongar la autonomía del paciente cuando ya no tiene posibilidad de expresar su propia voluntad.

Existen dos elementos básicos en tales directivas:

a)la declaración se realiza cuando el sujeto está en pleno dominio de sus facultades, en previsión del momento en que no lo estará;

b)la declaración consiste en instrucciones dadas a terceros y están referidas a intervenciones médicas sobre la persona misma del declarante (su salud, su cuerpo) ${ }^{13}$.

La prolongación de la vida artificialmente ha llegado a límites intolerables, instigada por profesionales que, en base a concepciones particulares desean hacer todo lo humanamente posible para prolongar un estado terminal, lo que genera naturales conflictos éticos.

El exceso terapéutico a que da lugar la "obstinación" se define a contrario con respecto a la intervención paliativa. El uno empieza donde termina la otra y el límite entre ambos está marcado, con relación al tratamiento mismo, por la referencia al punto de vista del enfermo o -en caso de imposibilidad de referirse directamente a tal punto de vista- por la subordinación del tratamiento en cuestión a una cuidadosa prueba de valoración que determine su adecuación (o, al contrario, su inadecuación) para conciliar la prolongación de la supervivencia, posibilitada por el tratamiento, con un nivel de

\footnotetext{
${ }^{13}$ Kemelmajer de Carlucci, A.: Las voluntades anticipadas, en: Bergel, S.D. (coord.): Bioética y Derechos Humanos, Lexis Nexis 2006, p. 249.
} 
calidad de vida que el enfermo consideraría, presumiblemente, como aceptable ${ }^{14}$. Precisamente cuando el enfermo no está en situación de expresar su voluntad dirigida a establecer tales límites, las directivas anticipadas juegan un papel central.

La normativa proyectada ya estaba contemplada en cierta forma en la Ley 26529 de derecho de los pacientes. Sin embargo existe en el proyecto una norma complementaria no contemplada por la Ley 26529. En efecto se establece que "puede designar a la persona o personas que han de expresar el consentimiento para los actos médicos y para ejercer la curatela”.

Este agregado es sumamente útil ya que el sujeto al momento de redactar las directivas anticipadas sólo puede prever algunas de las situaciones en las que eventualmente pueda verse comprometido; en cambio si -como lo autoriza el proyectodesigna un mandatario especial en situaciones límites para que exprese el consentimiento, se abre un espectro de posibilidades, pudiendo éste ejercer la curatela con el fin de respetar en la mayor medida la voluntad expresada.

10. A tiempo de cerrar estas reflexiones cabe destacar que la normativa proyectada contiene la mayor parte de las cuestiones que plantea la bioética en su relación con el derecho.

Si bien algunas normas ya preexistían con mínima diferencia en leyes especiales, considero que su incorporación al Código es acertada por cuanto las dota de un mayor sustento.

${ }^{14}$ Borsellino, P.: Op. cit., p. 228. 
Este puñado de normas sirve para mostrar las singulares relaciones entre bioética y derecho.

Detrás de la posición de quien considera al derecho instrumento de compatibilidad y de coexistencia de distintas visiones morales -enseña Borsellino- está la moral como horizonte en donde los individuos portadores de valores, de fines, de principios, con frecuencia divergentes, llegan pacíficamente a la individualización de las vías de acción que se adopten en las distintas circunstancias, gracias al reconocimiento que, con el único límite del daño a los otros, todo individuo (adulto y consciente) tiene derecho a vivir según sus propias convicciones y sus propios principios morales.

NOTA: El presente artículo fue enviado al Consejo de Redacción por el Doctor Salvador Bergel con anterioridad a la sanción de la Ley $\mathrm{N}^{\circ} 26.994$ (B.O. 08/10/2014), que aprobó el nuevo Código Civil y Comercial de la Nación. No obstante, esta circunstancia no le resta valor alguno al presente trabajo como aporte a la ciencia jurídica. 